\title{
Bradycardia after the use of atracurium
}

\author{
M L CARTER
}

\begin{abstract}
Four cases of severe bradycardia developed during surgery in patients given the neuromuscular blocking agent atracurium as part of the anaesthesia. In all cases sinus rhythm was restored by giving intravenous atropine.

It is recommended that in all operations in which vagal stimulation is expected patients should be given atropine as part of the premedication or induction sequence and should undergo full electrocardiographic monitoring during surgery.
\end{abstract}

\section{Introduction}

Atracurium is a recently introduced neuromuscular blocking agent which is stated to cause no clinically notable changes in heart rate or blood pressure in the range of recommended dosages. ${ }^{1}$

At this hospital atracurium has been used since its general release. I report four cases in which profound bradycardia requiring treatment occurred during that time.

\section{Case reports}

Case 1-A fit 84 year old woman undergoing cholecystectomy was given diazepam $10 \mathrm{mg}$ by mouth as premedication two hours before surgery. Anaesthesia was induced with methohexitone $70 \mathrm{mg}$, fentanyl $100 \mu \mathrm{g}$, and atracurium $35 \mathrm{mg}(0.75 \mathrm{mg} / \mathrm{kg})$ and mainfained with nitrous oxide and oxygen. When traction was applied to the gall bladder a nodal bradycardia of $30 / \mathrm{min}$ occurred. This responded promptly to intravenous administration of atropine $0.6 \mathrm{mg}$. The remainder of the period of anaesthesia was uneventful.

Case 2-A fit 60 year old woman undergoing surgery for retinal detachment was given diazepam $10 \mathrm{mg}$ by mouth as premedication, two hours before surgery. Anaesthesia was induced with fentanyl $200 \mu \mathrm{g}$, droperidol $5 \mathrm{mg}$, thiopentone $300 \mathrm{mg}$, and atracurium $35 \mathrm{mg}$ $(0.57 \mathrm{mg} / \mathrm{kg})$, and maintained with nitrous oxide and oxygen. During the anaesthetic a nodal bradycardia of $20 / \mathrm{min}$ occurred and was treated

Royal Shrewsbury Hospital, Shrewsbury

M L CARTER, MB, BS, FFARCS, registrar in anaesthetics with atropine $0.6 \mathrm{mg}$ intravenously. The electrocardiogram reverted to sinus rhythm. The remainder of the period of anaesthesia was uneventful.

Case 3-A fit 29 year old woman who had undergone an examination under anaesthesia that morning required an urgent ovarian cystectomy. The patient had not received any premedication. Anaesthesia was induced with thiopentone $350 \mathrm{mg}$, morphine $10 \mathrm{mg}$, and atracurium $50 \mathrm{mg}(0.625 \mathrm{mg} / \mathrm{kg})$ and maintained with nitrous oxide and oxygen. Peritoneal traction provoked a nodal bradycardia, but as her systolic blood pressure was $80 \mathrm{~mm} \mathrm{Hg}$ this did not require treatment. The bradycardia rapidly developed into complete heart block at a rate of $20 / \mathrm{min}$. Sinus rhythm was restored by giving atropine $0.6 \mathrm{mg}$ intravenously. The period of anaesthesia was subsequently uneventful.

Case 4-A fit 36 year old woman undergoing vaginal hysterectomy was given papaveretum $15 \mathrm{mg}$ and scopolamine $0.3 \mathrm{mg}$ as premedication. Anaesthesia was induced with thiopentone $300 \mathrm{mg}$ and atracurium $35 \mathrm{mg}(0.52 \mathrm{mg} / \mathrm{kg})$ and maintained with nitrous oxide, oxygen and halothane. During the procedure a sinus bradycardia of $35 / \mathrm{min}$ developed and this was treated with atropine $0.6 \mathrm{mg}$ intravenously. The heart rate increased to $70 / \mathrm{min}$. The patient's condition was reversed satisfactorily when atropine $1.2 \mathrm{mg}$ and neostigmine $2.5 \mathrm{mg}$ were given. In the recovery ward the heart rate decreased to $48 / \mathrm{min}$; atropine $0.6 \mathrm{mg}$ was given and the heart rate increased to $68 / \mathrm{min}$. The blood pressure was stable at $90 / 50 \mathrm{~mm} \mathrm{Hg}$. The subsequent recovery was uneventful.

\section{Comment}

Atracurium is a new neuromuscular blocking agent which undergoes Hofmann elimination, the spontaneous degradation of atracurium by non-enzymic mechanisms. It is facilitated by the combined electron withdrawal properties of the two $\beta$ linked ester carbonyl groups and the positively charged nitrogens of the quaternary ammonium groups. This occurs readily at physiological $\mathrm{pH}$ and temperature to give laudanosine as the main metabolite. ${ }^{2}$ Vagal blockade occurs after dosages eight to 16 times greater than those required for neuromuscular blockade and the effects on the sympathetic system are minimal. ${ }^{3}$

Since its general release, however, several cases of profound bradycardia requiring treatment with atropine have occurred at this hospital, and this has made the medical staff cautious in the use of this drug. At the time of writing neither Calmic Medical Division nor the Committee on Safety of Medicines has received any reports of problems of this nature, although 
cases of histamine release induced bronchospasm and hypotension have been reported to the Committee on Safety of Medicines.

Although in the past the combination of fentanyl, halothane, and curare has been noted for producing episodes of bradycardia, they do not seem to have been as profound or to have caused such concomitant changes in the QRS complexes as those observed with atracurium. There are two possibilities for this phenomenon: firstly, atracurium's lack of cardiovascular effects may mean that the cholinergic actions of other anaesthetic agents are unattenuated, and, secondly, perhaps a metabolite is having an effect. Laudanosine, the main metabolite, ${ }^{2}$ has a structure similar to apomorphine and may be contributory to these electrocardiographic changes.

Whatever the cause, I consider that it would be advisable in all operations in which vagal stimulation is expected that the patients undergo full electrocardiographic monitoring and that atropine should be given as part of the premedication or induction sequence.

\section{References}

${ }^{1}$ Payne JP, Hughes R. Evaluation of atracurium in anaesthetised man. $\mathrm{Br} \mathcal{F}$ Anaesth $1981 ; 53: 45-54$.

2 Stenlake JB. Ions-cyclic nucleotides-cholinergy. In: Stoclet JC, ed. Advances in pharmacology and therapeutics. Oxford and New York: Pergamon Press, 1979:303.

${ }^{3}$ Hughes R, and Chapple DJ. Pharmacology of atracurium. Br $\mathcal{J}$ Anaesth $1981 ; 53: 31-44$.

(Accepted 11 May 1983)

\title{
Recovery of renal function after prolonged dialysis and transplantation
}

\author{
T O NUNAN, E A STEVENS, D N CROFT, P J HILTON, N F JONES, A J WING
}

\begin{abstract}
Out of 250 patients with renal failure, seven $(2 \cdot 8 \%)$ treated by regular haemodialysis alone (four) or given cadaveric allografts (three) later showed recovery of function of their own kidneys lasting from one to four years. In the patients receiving haemodialysis alone recovery was easily recognised from their serum creatinine concentrations, but in those with transplants recovery was discovered unexpectedly during radionuclide scanning.

These findings suggest that recovery of renal function may be more common than generally recognised, which should be borne in mind when beginning renal replacement treatment and particularly when contemplating bilateral nephrectomy.
\end{abstract}

\section{Introduction}

Recovery of renal function in patients receiving long term dialysis or after renal transplantation has been reported. ${ }^{12}$ The registry of the European Dialysis and Transplant Association has collected 573 patients from a total of 91866 who had been treated by dialysis for more than six weeks in whom recovery lasted more than three months-an incidence of $0.6 \% .^{2}$ In our renal unit recovery occurred in seven of the first 250 patients $(2 \cdot 8 \%)$ accepted for renal replacement therapy. Recovery of renal function was proved by radionuclide imaging in three patients who had received kidney transplants. Without isotope scanning recovery of function by the patients' own kidneys would not have been detected.

\footnotetext{
Departments of Renal and Nuclear Medicine, St Thomas's Hospital, London SE1 7EH

T O NUNAN, MSC, MRCP, senior medical registrar

E A STEVENS, SRN, HV, nursing officer

D N CROFT, DM, FRCP, consultant physician

P J HILTON, MD, FRCP, consultant physician

N F JONES, MD, FRCP, consultant physician

A J WING, DM, FRCP, consultant physician

Correspondence to: Dr T O Nunan.
}

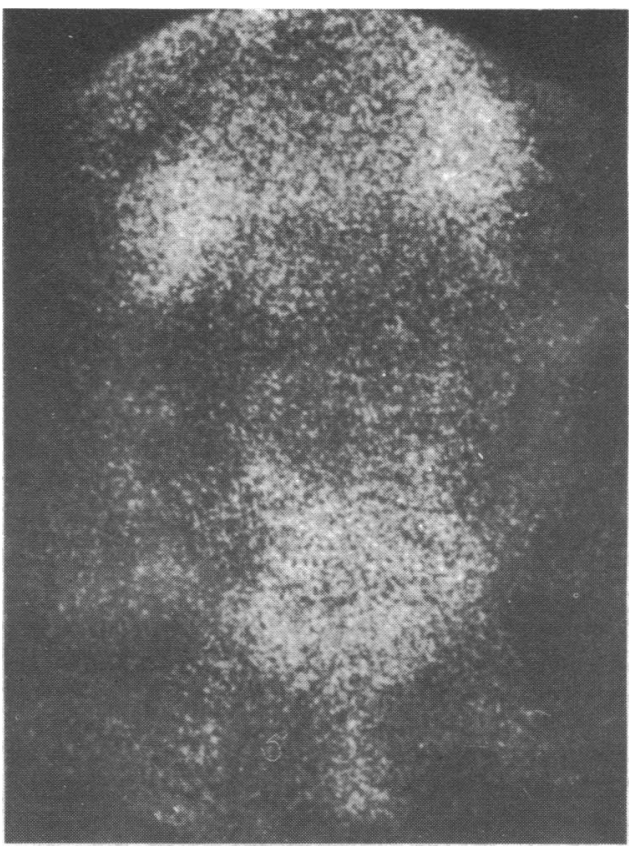

99mTc-DTPA gammacamera scan of transplant recipient with crescentic glomerulonephritis showing uptake by her own two kidneys.

\section{Present series}

Four of the seven patients we describe had received regular haemodialysis as the only form of renal replacement therapy. Their primary renal diseases were mesangiocapillary glomerulonephritis in two, crescentic glomerulonephritis in one, and Goodpasture's syndrome in one. The periods of dialysis before detection of recovery of renal function were $13,41,13$, and 12 weeks respectively. In the two patients with mesangiocapillary glomerulonephritis recovery of renal function was sufficient to remove the need for dialysis for 50 and 41 weeks respectively. The patient with crescentic glomerulonephritis remained well for four years with a serum creatinine concentration of $380 \mu \mathrm{mol} / 1(4.3 \mathrm{mg} / 100 \mathrm{ml})$ or less before her renal disease recurred and dialysis again became necessary. The patient with Goodpasture's 